\title{
A EXPRESSÃO DE GENES REPARADORES DO DNA NOS TUMORES SINCRÔNICOS DE CÂNCER COLORRETAL ESPORÁDICO
}

\section{DNA repair gene expression in synchronic tumors of sporadic colorectal cancer}

\author{
Igor PROSCURSHIM, Rodrigo Oliva PEREZ, Rosa Maria Nascimento SANTOS,
} Edson Luiz ZAPAROLI, Desidério Roberto KISS, Angelita HABR-GAMA

ABCDDV/518

Proscurshim I, Perez RO, Santos RMN, Zaparolli EL, Kiss D, Habr-Gama A. A expressão de genes reparadores do DNA nos tumores sincrônicos de câncer colorretal esporádico. ABCD Arq Bras Cir Dig 2007; 20(1):12-6.

RESUMO - Racional - Um dos mecanismos genéticos presentes em aproximadamente $80 \%$ dos pacientes com síndrome hereditária não-polipóide do câncer colorretal são os defeitos nos genes reparadores de DNA, como o MSH2, MSH6 e MLH1, onde os tumores sincrônicos são relativamente freqüentes. Já no câncer colorretal esporádico as lesões sincrônicas são raras. Objetivo - Verificar se o mesmo mecanismo genético presente no síndrome hereditária não-polipóide do câncer colorretal está presente no câncer colorretal esporádico que apresentam com lesões sincrônicas. Métodos - Foram incluídos no estudo todos os pacientes com câncer colorretal sincrônico não síndrome hereditária não-polipóide do câncer colorretal. Imunoistoquímica com anticorpos para MSH2,MSH6, e MLH1 foi realizada para cada tumor. Resultados - Todos os pacientes apresentaram expressão normal de MSH2 e MLH1. O único gene com imunoexpressão alterada foi o MSH6. Conclusão - Possivelmente outro mecanismo genético seja responsável pelo surgimento de dois tumores sincrônicos no câncer colorretal esporádico.

DESCRITORES - Neoplasias colorretais. Imunoistoquímica, adenocarcinoma.

\section{INTRODUÇÃO}

O câncer colorretal (CCR) persiste como uma das neoplasias mais freqüentes no mundo ocidental, estimando-se aproximadamente 150 mil casos novos nos Estados Unidos e cerca de 20 mil no Brasil $1^{7,15}$

A descoberta de mecanismos genéticos e moleculares envolvidos no processo da carcinogênese colorretal permitiu a identificação de uma síndrome hereditária com grande suscetibilidade para algumas neoplasias (além do CCR) conhecida como síndrome hereditária não-polipóide do câncer colorretal (HNPCC - Hereditary Non-Polyposis Colorectal Cancer). Atualmente, acredita-se que estes pacientes possam corresponder a cerca de $10 \%$ dos casos de neoplasia colorretal.

Nesta síndrome hereditária, acredita-se que o mecanismo genético envolvido no processo de carcinogênese inclui defeitos no mecanismo de reparo do DNA, levando à ocorrência de erros freqüentes de replicação - fenômeno conhecido como instabilidade de microssatélites -. Com isso, foram identificadas alterações nos genes de proteínas envolvidas no processo de reparo do DNA, sendo os genes mais frequentemente afetados o MSH2, MLH1 e $\mathrm{MSH}^{10}$.

Ao contrário, tumores ditos esporádicos, estariam associados a mutação e ativação de proto-oncogenes (mais

Trabalho realizado no Departamento de Gastroenterologia da Faculdade de Medicina da Universidade de São Paulo, São Paulo, SP, Brasil.

Endereço para correspondência: Igor Proscurshim, e-mail: praskurkin@gmail.com frequentemente o K-ras) assim como a deleção de áreas cromossômicas de genes supressores de tumor (como p53, DCC e APC) $)^{5}$.

Além de estar associada a mecanismos genéticos e moleculares distintos das neoplasias colorretais usuais, pacientes com HNPCC apresentam características clinicas, patológicas e prognóstico que também os diferenciam dos pacientes com neoplasia esporádica. Entre estas características, a presença de tumores sincrônicos nestes pacientes com HNPCC é achado muito mais freqüente quando comparado aos pacientes com tumor esporádico ${ }^{8,11,14}$.

Apesar disso, uma parcela significativa (até 15\%) dos pacientes com tumor esporádico pode apresentar alterações genéticas compatíveis com defeito no mecanismo de reparo do DNA e instabilidade de microssatélites ${ }^{8}$.A ocorrência deste fenômeno poderia justificar a presença nestes pacientes com tumor esporádico de características clinicas e patológicas semelhantes aos tumores de pacientes com HNPCC.

Por esta razão decidiu-se, por objetivo deste trabalho, investigar as alterações dos genes responsáveis pelo mecanismo de reparo do DNA em pacientes com tumor esporádico e manifestação clínica muito característica dos tumores HNPCC, a presença de tumores sincrônicos.

\section{MÉTODOS}

Pacientes com adenocarcinoma do cólon ou do reto tratados pela Disciplina de Coloproctologia da Faculdade 
de Medicina da Universidade de São Paulo, São Paulo, SP, Brasil, no período de 1984 e 2004 foram incluídos no estudo, mas somente os com neoplasia sincrônica, submetidos a tratamento cirúrgico radical único. Pacientes com HNPCC determinado pelos critérios de Amsterdam ou Bethesda foram excluídos.

Os dados clínicos e seguimento tardio foram obtidos através de consulta ao prontuário médico do hospital. Pacientes com dados indisponíveis, foram submetidos a contato telefônico para atualização dos dados. A localização dos tumores foi classificada em cólon direito (tumores do ceco ao cólon transverso distal), cólon esquerdo (do transverso distal ao sigmóide) e reto.

Os resultados dos exames anátomo-patológicos dos tumores foram todos revisados e confirmados.

\section{Imunoistoquímica}

Para o rastreamento de possíveis alterações gênicas relacionadas a genes que controlam a instabilidade de microsatélites, foi realizada a pesquisa de antígenos hMSH2, hMLH1 e hMSH6, mediante incubação com os anticorpos hMSH2 (clone G219-1129), hMLH1 (clone G168-728) e hMSH6 (clone 44) (Pharmigen, San Diego,CA,EUA), padronizados no laboratório de imunoistoquímica da Divisão de Patologia do Instituto Adolfo Lutz. O método empregado foi o sistema de amplificação de sinal tiramida livre de biotina (DakoCytomation CSA II, Carpinteria, CA 93013 EUA).

Os blocos de tecido foram embebidos em parafina, fixados em formalina a $10 \%$ e incluídos em parafina, nos quais foram realizados cortes histológicos com $4 \mu \mathrm{m}$ de espessura e montados em lâminas cobertas com silano. Os fragmentos foram desparafinados em xilóis e re-hidratados em álcoois. A atividade da peroxidase endógena foi bloqueada por imersão em peróxido de hidrogênio (Merck S.A. Indústrias Químicas, Rio de Janeiro, RJ), três trocas de 5 minutos. Foi utilizado o método da panela de pressão para a recuperação antigênica com tampão citrato $\mathrm{pH} 6,0$. As lâminas foram removidas e lavadas em tampão fosfato pH 7,4 (PBS).

Os anticorpos monoclonais primários foram aplicados nas titulações padronizadas para o hMSH2 1:400, hMLH1 1:150 e hMSH6 1:2000 (Pharmigen, San Diego,CA,EUA). Os cortes foram incubados em câmara úmida a $37^{\circ} \mathrm{C}$, por 30 minutos e em seguida overnight $4^{\circ} \mathrm{C}$. A seguir os tecidos foram lavados em tampão PBS, e incubados a $37^{\circ} \mathrm{C}$ com anticorpo secundário conjugado a peroxidase, reagente amplificador e o anticorpo anti-fluoresceína conjugada a peroxidase (CSA II DakoCytomation). Todas essas etapas foram precedidas das lavagens com PBS. O sítios antigênicos foram identificados usando o substrato cromogênico 3'3 diaminobenzidina tetrahidrocloreto (SIGMA-Aldrich Co. St. Louis, EUA) com $1 \mathrm{mg} / \mathrm{mL}$ com $0,1 \%$ (vol/vol) de peróxido de hidrogênio. Os cortes foram contra corados com hematoxilina de Harris, desidratados e as lâminas foram montadas com meio de Entellan ${ }^{\circledR}$ neu (Merck KGaAAlemanha) $)^{3,4}$.

\section{Interpretação dos resutados}

Tumores com imunoexpressão ausente ( $0 \%$ de células) foram considerados negativos enquanto que imunoexpressão de qualquer porcentual de células tumorais em qualquer intensidade foi considerada positiva. Tecido colorretal normal, bem como linfócitos, puderam ser utilizados como controles positivos da reação.

\section{RESULTADOS}

No período de estudo foram identificados 17 pacientes com tumores colorretais sincrônicos sem critérios clínicos para o diagnóstico de HNPCC, considerados esporádicos. Apenas 15 pacientes apresentavam material dos dois (ou mais) tumores disponível para realização de novos cortes para as reações de imunoistoquímica.

A idade média dos pacientes foi de $63,0( \pm 15)$ anos, variando entre 39 e 84 . Sete pacientes eram do sexo feminino enquanto oito do masculino (Tabela 1).

TABELA 1 - Características clínicas dos pacientes com tumor colorretal esporádico sincrônico

\begin{tabular}{ll}
\hline Idade & \\
\hline Média & $63 \pm 15$ anos \\
Intervalo & $39-84$ anos \\
\hline Sexo & \\
\hline Masculino & $8 / 15$ \\
Feminino & $7 / 15$ \\
\hline
\end{tabular}

Em todos os pacientes (100\%) havia apenas duas lesões sincrônicas consideradas adenocarcinomas invasivos. O estadiamento anátomo-patológico, utilizando o maior valor de cada parâmetro, revelou dois pacientes $(13 \%)$ com tumores invadindo até a camada muscular (pT2) e 13 (87\%) com invasão de todas as camadas do órgão (pT3). Em relação à presença de metástases linfonodais, seis pacientes (40\%) não apresentaram metástases em nenhum dos linfonodos dissecados (pN0) enquanto que nove pacientes $(60 \%)$ apresentaram pelo menos um linfonodo comprometido (pN1). Dois pacientes $(13 \%)$ apresentavam metástases em sítios distantes (M1) (Tabela 2).

TABELA 2 - Características anatomopatológicas dos pacientes com tumor colorretal sincrônico esporádico

\begin{tabular}{ccc}
\hline AJCC/UICC & & $\mathbf{n}$ \\
\hline & 1 & 0 \\
& 2 & 2 \\
& 3 & 13 \\
& 4 & 0 \\
\hline \multirow{2}{*}{$\mathrm{pN}$} & 0 & 6 \\
& 1 & 6 \\
$\mathrm{~N}$ & 2 & 3 \\
\hline \multirow{2}{*}{$\mathrm{M}$} & 0 & 13 \\
& 1 & 2 \\
\hline \multirow{2}{*}{ Estadio } & I & 2 \\
& II & 5 \\
& III & 6 \\
& IV & 2 \\
\hline
\end{tabular}


Seis pacientes (40\%) apresentavam tumor localizado no mesmo segmento intestinal, sendo um (17\%) com os dois tumores localizados no reto, um (17\%) com os dois tumores localidos no cólon esquerdo e quatro (66\%) com os dois tumores localizados no cólon direito. Os nove pacientes restantes apresentavam tumores em segmentos intestinais distintos $(60 \%)$. A tabela 3 resume as características de localização e estadiamento destes tumores.

TABELA 3 - Características dos tumores sincrônicos

\begin{tabular}{cccc}
\hline & & Tumor distal & Tumor proximal \\
\hline Localização & Reto & 7 & 1 \\
& Esquerdo & 4 & 2 \\
Tamanho (cm) & Direito & 4 & 12 \\
\hline AJCC/UICC Estadio & & $5.8 \pm 2.5$ & $4.6 \pm 2.2$ \\
\hline \multirow{2}{*}{$\mathrm{pT}$} & 0 & & \\
& & 0 & 0 \\
& 1 & 1 & 1 \\
& 2 & 0 & 2 \\
$\mathrm{pN}$ & 3 & 12 & 3 \\
& 4 & 0 & 0 \\
\hline & 0 & 7 & 8 \\
& 1 & 6 & 6 \\
\hline
\end{tabular}

Cólon direito - Ceco ao transverso distal

Cólon esquerdo - Descendente ao sigmóide

Reto - Reto

Considerando todas as lesões, haviam oito tumores (27\%) localizados no reto, seis $(20 \%)$ no cólon esquerdo e $16(53 \%)$ no cólon direito. Considerando a profundidade de invasão na parede do órgão, havia dois tumores (7\%) limitados à mucosa (pTis), dois $(7 \%)$ com invasão da submucosa (pT1), cincco (16\%) com invasão até a camada muscular (pT2) e $21(70 \%)$ com invasão de todas as camadas do intestino (pT3). No que diz respeito à presença de metástases linfonodais, 15 pacientes $(50 \%)$ não as apresentavam ( $\mathrm{pN} 0)$.

A imunoexpressão de MSH2 e MLH1 foram consideradas positivas em todos os tumores e todo tecido normal adjacente de todos os pacientes (100\%) (Figura 1). Apenas um paciente apresentou ausência de expressão de MSH6 nos dois tumores enquanto que o tecido normal adjacente apresentou expressão positiva para este anticorpo (Figura 2).

O seguimento médio dos pacientes foi de 24,9 meses $( \pm 20,7)$ variando de seis à 78 meses. Nenhum dos pacientes apresentou recidiva da doença ou mortalidade durante o seguimento tardio.

\section{DISCUSSÃO}

Atualmente, considera-se que o câncer é uma doença genética, de tal maneira que mutações acumuladas em uma célula ou clone de células pode lhe conferir características distintas de proliferação e diferenciação celular. Estas mutações podem ocorrer de maneira esporádica durante a vida ou então hereditárias, quando são transmitidas através de linhagem germinativa. Neste segundo caso, algumas mutações hereditárias podem conferir suscetibilidade ao câncer ${ }^{6}$.

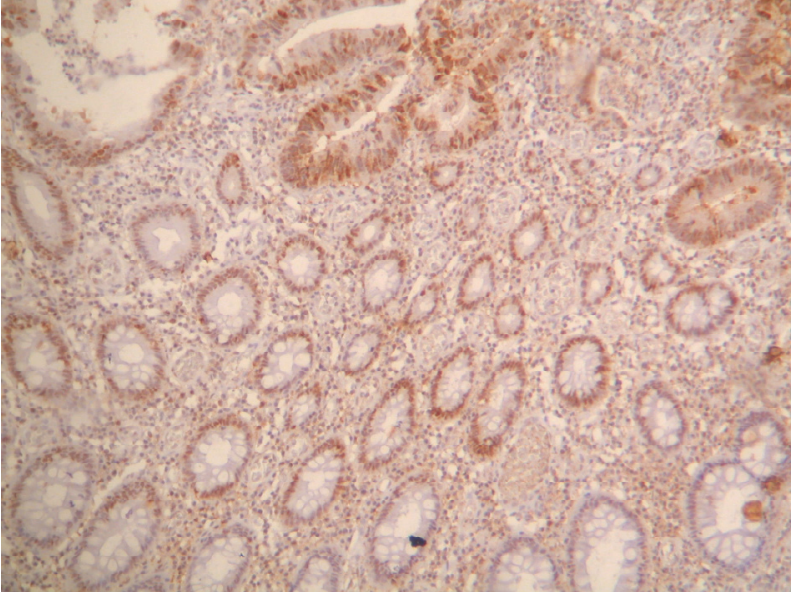

FIGURA 1 - Tumor corado com anticorpo para MSH1 mostrando a positividade de immunoexpressão no tecido tumoral e no tecido normal adjacente

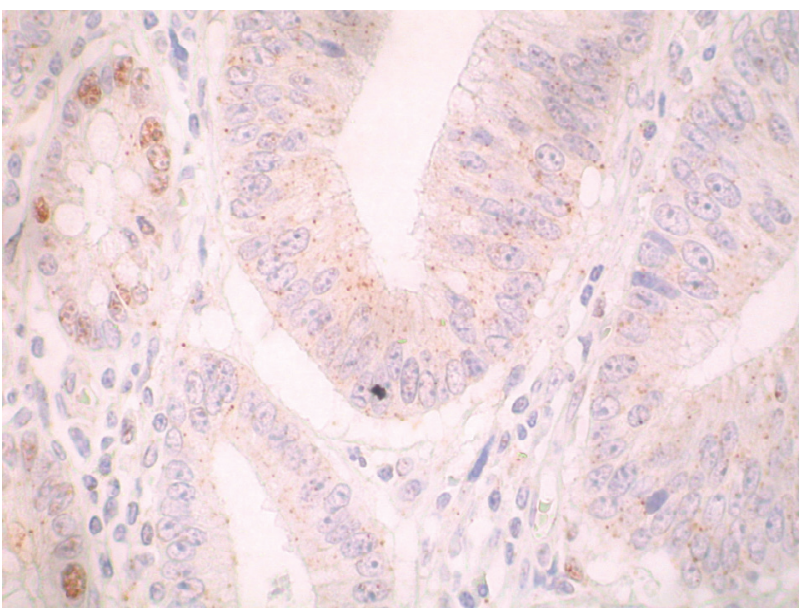

FIGURA 2 - Tumor corado com anticorpo para MSH6 mostrando a ausência de immunoexpressão no tumor e a positividade no tecido normal adjacente

Desde o início do século, vem sendo notada a ocorrência do câncer colorretal hereditário na ausência de polipose que, além do caráter hereditário, apresentava algumas características clínicas e patológicas distintas dos tumores colorretais ditos esporádicos ${ }^{1,18}$. Esta síndrome, apresenta padrão de herança autossômica dominante e pode corresponder a até $10 \%$ de todos os casos de câncer colorretal ${ }^{6}$. Além disso, estes pacientes apresentavam com freqüência idade precoce no momento do diagnóstico com média aproximada de 45 anos $^{20}$.

Em 1991 foram estabelecidos critérios para o diagnóstico clínico e epidemiológico desta síndrome - conhecidos como critérios de Amsterdam -, que incluem o diagnóstico de três familiares, duas gerações consecutivas e pelo menos um paciente com idade inferior a $50 \operatorname{anos}^{12,21}$. Estes pacientes freqüentemente apresentavam tumores de localização proximal, com componente mucinoso, estadiamento pTNM avançado, maior risco de lesões sincrônicas e metacrônicas ${ }^{13}$. Apesar de algumas características reconhecidamente associadas a pior prognóstico, 
curiosamente estes pacientes parecem estar associados a melhores resultados de sobrevivência tardia e menor risco de recidiva ${ }^{19}$. Possivelmente, uma das justificativas para estes últimos achados seria a presença de infiltrado inflamatório peritumoral, freqüentemente observado nestes tumores e podendo refletir maior efetividade do sistema imunológico hospedeiro versus tumor ${ }^{2,16}$.

Independente disso, estes pacientes pareciam apresentar doença distinta daquela dos com tumor colorretal esporádico. Por esta razão, era de se esperar que houvesse uma explicação genética e molecular que justificasse tal diferenças. De fato, a identificação de áreas cromossômicas que segregavam de maneira semelhante, a doença em famílias HNPCC permitiu a localização dos genes responsáveis por esta síndrome, que codificavam proteínas envolvidas no processo de reparo de DNA ${ }^{9}$. Muito embora vários genes que têm papel no controle de reparo de DNA tenham sido identificados, acredita-se que mais de $90 \%$ dos casos de HNPCC sejam decorrentes de mutações nos genes MSH2 e MLH $1^{17}$. Apesar disso, as mutações não são comuns entre os pacientes nem estão localizadas em áreas mais suscetíveis ("hot spots") $)^{22}$. Outros genes foram identificados e parece haver correlação entre o gene alterado e algumas manifestações clínicas. Especificamente para o MSH6, a associação de tumores extra-intestinais, como o câncer do endométrio, parece ser freqüente .

Uma parcela significativa dos pacientes com neoplasia esporádica apresenta alterações genéticas somáticas semelhantes aos tumores HNPCC. Acredita-se que estes pacientes, com alterações genéticas e moleculares semelhantes aos tumores HNPCC apresentem fenótipo e prognóstico semelhantes. Como o evento de tumores sincrônicos é muito raro, surge a hipótese de que estes pacientes tenham tumores com alterações genéticas do mecanismo de reparo do DNA, semelhantes aos tumores HNPCC.

A utilização da imunoistoquímica para determinação retrospectiva destas alterações parece ser oportuna em função da grande variabilidade de alterações genéticas específicas, de tal maneira que a visualização do produto final pode ter significado clínico mais direto.

Nesta série, os pacientes com tumores sincrônicos apresentavam idade média bastante superior ( 63 anos) àquela encontrada para pacientes HNPCC (45 anos), fato esperado uma vez que seriam necessárias mutações somáticas dos genes reparadores de DNA nos dois alelos, ao contrário do HNPCC em que um alelo está mutado desde o nascimento do indivíduo. Certamente, fatores ambientais estariam envolvidos no processo de mutação dos alelos exigindo tempo significativamente maior que o necessário para pacientes com HNPCC. Além disso, a localização proximal no cólon direito foi achado freqüente $(53 \%)$ nesta série coincidindo com os achados em tumores de pacientes HNPCC.

Curiosamente, os tumores sincrônicos esporádicos apresentaram freqüente invasão transmural do intestino $(70 \%)$ e presença de metástases linfonodais (50\%), levando a estadiamentos mais avançados da doença em mais de $60 \%$ dos casos (estádio III). Apesar disso, observou-se da mesma forma que nos tumores HNPCC, bom prognóstico tardio, uma vez que não foram observadas recidivas em intervalo médio de seguimento de mais de dois anos. Por estas razões, esperavase encontrar com grande freqüência $(>90 \%)$ alterações da imunoexpressão dos genes estudados semelhantes às taxas observadas nos tumores HNPCC. Contudo, a expressão negativa (refletindo inativação por qualquer mecanismo) foi observada em apenas um paciente, utilizando anticorpos anti-MSH6, que é achado muito menos freqüente quando comparado aos genes MSH2 e MLH1.

\section{CONCLUSÃO}

Os pacientes com tumor colorretal esporádico sincrônico apresentaram características clinicas e patológicas semelhantes aos com tumores HNPCC no que diz respeito a localização dos tumores, estadiamento anatomopatológico e sobrevida tardia. Ao contrário, a identificação de alterações dos genes de reparo do DNA mais freqüentemente encontradas nos tumores HNPCC não foram identificadas nos tumores sincrônicos esporádicos. Estes achados indicam que embora estes tumores sincrônicos esporádicos possam ter semelhanças clínicas e patológicas com tumores HNPCC, o mecanismo molecular pode ser distinto, inclusive com a participação de outros genes reparadores de DNA não relacionados ao HNPCC.

\section{AGRADECIMENTOS}

Os autores agradecem aos Drs. Regina Maria Catarino, Cristovam Scapulatempo Neto e Venâncio Avancini Ferreira Alves do Laboratório de Imunoistoquímica da Divisão de Patologia do Instituto Adolfo Lutz, São Paulo, SP, Brasil, pelo auxílio recebido na análise do material deste estudo.

Proscurshim I, Perez RO, Santos RMN, Zaparolli EL, Kiss D, Habr-Gama A. DNA repair gene expression in synchronic tumors of sporadic colorectal cancer. ABCD Arq Bras Cir Dig 2007; 20(1):12-6.

ABSTRACT - Background - Mismatch repair genes (such as MSH2, MLH1 and MSH6) mutations are present in over 80\% of hereditary non-polyposis colorectal cancer tumors, which frequently exhibit synchronous lesions. Sporadic colorectal cancer is rarely associated with synchronous lesions. Aim - To investigate whether or not the same genetic mechanism present in hereditary non-polyposis colorectal cancer is present in synchronous sporadic colorectal cancer. Methods - Patients with sporadic synchronous colorectal adenocarcinomas were included in the study. Immunohistochemistry was performed using MSH2, MLH1 and MSH6 antibodies. Results - All patients had two synchoronous lesions. None of them had altered MSH2 or MLH1 expression. One patient had altered MSH6 expression in both tumors. Conclusion - Possibly, other molecular mechanisms are involved in carcinogenesis of sporadic synchronous colorectal cancer.

HEADINGS - Colorectal neoplasms. Immunohistochemistry. Adenocarcinoma. 


\section{REFERÊNCIAS}

1. Aaltonen LA. Hereditary intestinal cancer. Semin Cancer Biol 2000;10(4):28998.

2. Aaltonen LA, Peltomaki P, Leach FS, Sistonen P, Pylkkanen L, Mecklin JP, Jarvinen H, Powell SM, Jen J, Hamilton SR, et al. Clues to the pathogenesis of familial colorectal cancer. Science 1993;260(5109):812-6.

3. Bobrow MN, Harris TD, Shaughnessy KJ, Litt GJ. Catalyzed reporter deposition, a novel method of signal amplification. Application to immunoassays. J Immunol Methods 1989;125(1-2):279-85.

4. Bobrow MN, Shaughnessy KJ, Litt GJ. Catalyzed reporter deposition, a novel method of signal amplification. II. Application to membrane immunoassays. J Immunol Methods 1991;137(1):103-12.

5. Bodmer WF, Cottrell S, FrischaufAM, Kerr IB, Murday VA, Rowan AJ, Smith MF, Solomon E, Thomas H, Varesco L. Genetic analysis of colorectal cancer. Princess Takamatsu Symp 1989;20:49-59.

6. Chung DC, Rustgi AK. The hereditary nonpolyposis colorectal cancer syndrome: genetics and clinical implications. Ann Intern Med 2003;138(7):56070 .

7. Jemal A, Murray T, Ward E, Samuels A, Tiwari RC, Ghafoor A, Feuer EJ, Thun MJ. Cancer statistics, 2005. CA Cancer J Clin 2005;55(1):10-30.

8. Kim YS. Molecular genetics of colorectal cancer. Digestion 1997;58 Suppl 1:65-8.

9. Lynch HT, de la Chapelle A. Genetic susceptibility to non-polyposis colorectal cancer. J Med Genet 1999;36(11):801-18.

10. Lynch HT, de la Chapelle A. Hereditary colorectal cancer. N Engl J Med 2003;348(10):919-32.

11. Lynch HT, Kimberling W, Albano WA, Lynch JF, Biscone K, Schuelke GS, Sandberg AA, Lipkin M, Deschner EE, Mikol YB, et al. Hereditary nonpolyposis colorectal cancer (Lynch syndromes I and II). I. Clinical description of resource. Cancer 1985;56(4):934-8.

12. Lynch HT, Lanspa SJ, Boman BM, Smyrk T, Watson P, Lynch JF, Lynch PM, Cristofaro G, Bufo P, Tauro AV, et al. Hereditary nonpolyposis colorectal cancer--Lynch syndromes I and II. Gastroenterol Clin North Am 1988;17(4):679712 .
13. Lynch HT, Watson P, Lanspa SJ, Marcus J, Smyrk T, Fitzgibbons RJ, Jr., Kriegler M, Lynch JF. Natural history of colorectal cancer in hereditary nonpolyposis colorectal cancer (Lynch syndromes I and II). Dis Colon Rectum 1988;31(6):439-44.

14. Park JG, Kim IJ. [Hereditary colorectal cancer]. Korean J Gastroenterol 2005;45(2):78-87.

15. Parkin DM, Bray F, Ferlay J, Pisani P. Global cancer statistics, 2002. CA Cancer J Clin 2005;55(2):74-108.

16. Peltomaki P, Aaltonen LA, Sistonen P, Pylkkanen L, Mecklin JP, Jarvinen H, Green JS, Jass JR, Weber JL, Leach FS, et al. Genetic mapping of a locus predisposing to human colorectal cancer. Science 1993;260(5109):810-2.

17. Peltomaki P, Vasen HF. Mutations predisposing to hereditary nonpolyposis colorectal cancer: database and results of a collaborative study. The International Collaborative Group on Hereditary Nonpolyposis Colorectal Cancer. Gastroenterology 1997;113(4):1146-58.

18. Samowitz WS, Curtin K, Lin HH, Robertson MA, Schaffer D, Nichols M, Gruenthal K, Leppert MF, Slattery ML. The colon cancer burden of genetically defined hereditary nonpolyposis colon cancer. Gastroenterology 2001;121(4):830-8.

19. Smyrk TC, Watson P, Kaul K, Lynch HT. Tumor-infiltrating lymphocytes are a marker for microsatellite instability in colorectal carcinoma. Cancer 2001;91(12):2417-22

20. Vasen HF, Mecklin JP, Khan PM, Lynch HT. The International Collaborative Group on Hereditary Non-Polyposis Colorectal Cancer (ICG-HNPCC). Dis Colon Rectum 1991;34(5):424-5.

21. Vasen HF, Nagengast FM, Khan PM. Interval cancers in hereditary non-polyposis colorectal cancer (Lynch syndrome). Lancet 1995;345(8958):1183-4.

22. Wu Y, Berends MJ, Mensink RG, Kempinga C, Sijmons RH, van Der Zee AG, Hollema H, Kleibeuker JH, Buys CH, Hofstra RM. Association of hereditary nonpolyposis colorectal cancer-related tumors displaying low microsatellite instability with MSH6 germline mutations. Am J Hum Genet 1999;65(5):12918.

Conflito de interesse: não há Fonte financiadora: não há Recebido para publicação em: 02/10/2006 Aceito para publicação em: 17/12/2006 